\title{
Positive expression of programmed death ligand-I correlates with superior outcomes and might be a therapeutic target in primary pulmonary lymphoepithelioma-like carcinoma
}

\author{
This article was published in the following Dove Press journal: \\ OncoTargets and Therapy \\ 15 June 2015 \\ Number of times this article has been viewed
}

\section{Li Jiang ${ }^{1,2, *}$ \\ Liang Wang ${ }^{1,3, *}$ \\ Peng-fei Li ${ }^{1,4, *}$ \\ Xin-ke Zhang ${ }^{1,5}$ \\ Jie-wei Chen ${ }^{1,5}$ \\ Hui-juan Qiu', ${ }^{1,2}$ \\ Xiao-dong $\mathrm{Wu}^{6}$ \\ Bei Zhang ${ }^{1,2}$}

'State Key Laboratory of Oncology in South China, Collaborative Innovation Center of Cancer Medicine, ${ }^{2}$ VIP

Region, ${ }^{3}$ Department of Hematologic Oncology, ${ }^{4}$ Department of Oncology, ${ }^{5}$ Department of Pathology, Sun

Yat-sen University Cancer Center, ${ }^{6}$ Department of Integrative Medicine, Cancer Center of Guangzhou Medical University, Guangzhou, People's

Republic of China

*These authors contributed equally to this work

Correspondence: Bei Zhang State Key Laboratory of Oncology in South China, Collaborative Innovation Center of Cancer Medicine, VIP region, Sun Yat-sen University Cancer Center, 65I Dongfeng East Road, Guangzhou, Guangdong 510060, People's Republic of China

Tel +862087343455

Fax +86208734 3455

Email zhangbeisysucc@I63.com

Xiao-dong Wu

Heng Zhigang 78, Yue Xiu district, Guangzhou, 510000, People's Republic of China

Email wuxiaodongsysucc@126.com
Background: Primary pulmonary lymphoepithelioma-like carcinoma (LELC) is a rare subtype of non-small cell lung cancer (NSCLC), and no effective treatments have been defined for advanced disease. Programmed cell death-ligand 1 (PD-L1) is expressed in a group of cancers that may be suitable targets for specific immunotherapy.

Methods: This study investigated the expression and clinical value of PD-L1 in pulmonary LELC. Seventy-nine patients with pulmonary LELC were investigated. Paraffin-embedded tumor sections were stained with PD-L1 antibody. Correlations of PD-L1 expression with clinicopathologic parameters and outcomes were analyzed.

Results: Fifty patients (63.3\%) were PD-L1 positive. The 3-year and 5-year progression-free survival (PFS) rate was $76.0 \%$ and $68.0 \%$, respectively, and the 3-year and 5-year overall survival (OS) rate was $88.0 \%$ and $79.0 \%$, respectively. Kaplan-Meier analysis revealed that patients with positive PD-L1 expression had longer PFS and OS than those with negative PD-L1 expression $(P=0.019$ and $P=0.042$, respectively). In a multivariate Cox regression model including age, tumor size, stage, and PD-L1 expression status, the latter three factors were found to be independent predictors of PFS ( $P=0.023, P=0.000$, and $P=0.009$, respectively), but only stage was found to be an independent factor for OS $(P=0.007)$, and PD-L1 expression status showed a trend to be independently correlated with $\operatorname{OS}(P=0.080)$.

Conclusion: Our results showed that a large proportion of patients with pulmonary LELC had positive expression of PD-L1, supporting the potential use of anti-PD-1/PD-L1-targeted therapies in this distinct type of NSCLC.

Keywords: pulmonary lymphoepithelioma-like carcinoma, programmed cell death-ligand 1, Epstein-Barr virus, tumor-infiltrating lymphocytes, prognosis

\section{Introduction}

Primary pulmonary lymphoepithelioma-like carcinoma (LELC) was first reported by Begin et $\mathrm{al}^{1}$ in 1987, and is classified as a type of large-cell carcinoma based on the World Health Organization classification. ${ }^{2}$ Histopathologically, it is similar to nasopharyngeal carcinoma, ${ }^{3}$ and has a close relationship with Epstein-Barr virus (EBV) infection. ${ }^{4}$ Over the past two decades, fewer than 300 cases have been reported in the literature, including no more than 20 cases from Western populations. ${ }^{5,6}$ Patients with lung LELC have better outcomes than those with adenocarcinoma or squamous cell carcinoma of the lung. ${ }^{7}$ Radical surgery is usually performed in early-stage disease. For advanced disease, the treatment strategy is still controversial due to the rarity of lung LELC, and a combination of chemotherapy, surgery, and radiotherapy could 
be considered. Epidermal growth factor receptor (EGFR) mutations $^{8}$ and echinoderm microtubule-associated proteinlike 4-anaplastic lymphoma kinase (EML4-ALK) fusion gene $^{9}$ have been found to be driver genes in some patients with non-small cell lung cancer (NSCLC). Patients who harbor EGFR mutations are sensitive to EGFR tyrosine kinase inhibitors ${ }^{10}$ and those with EML4-ALK respond well to crizotinib. ${ }^{11}$ However, EGFR mutations and ALK rearrangement have been reported to be rare in pulmonary LELCs, ${ }^{6,12}$ suggesting that EGFR-targeted and ALK-targeted therapies are not suitable for patients with advanced pulmonary LELC. Thus, other treatment approaches, such as immune therapies, should be investigated to improve the outcome of patients with advanced pulmonary LELC.

Tumor-infiltrating lymphocytes (TILs) are generally considered to reflect the primary host immune response against tumors. However, in patients with various types of cancer, the immune system is often characterized by the presence of a variety of inhibitory mechanisms preventing lymphocyte activation. ${ }^{13}$ Programmed cell death receptor 1 (PD-1) is typically expressed by activated lymphocytes. ${ }^{14}$ Its engagement by specific ligands, including PD ligand 1 (PD-L1) and PD ligand 2, triggers downregulation of antigen-stimulated lymphocyte proliferation and cytokine production, ${ }^{15,16}$ ultimately resulting in lymphocyte "exhaustion" and induction of immune tolerance. ${ }^{17,18}$

Recently, a number of studies have found upregulated expression of PD-1 ligands in malignant cells, which has been suggested to play a central role in tumor-immune system interaction. Thus, by triggering PD-1, cancer cells might shut down specific immune responses. ${ }^{19}$ PD-L1 has been reported to be expressed by tumor cells of different origin, including renal cell carcinoma, ${ }^{20}$ squamous cell carcinoma of the head and neck, ${ }^{21}$ esophageal cancer, ${ }^{22}$ and NSCLC. ${ }^{23}$ Capitalizing on this background, PD-1/PD-L1 blockade by anti-PD-1 or anti-PD-L1 monoclonal antibodies has been envisaged as an appealing option to activate the host immune system to eradicate tumors. Recently, promising results of Phase I clinical trials involving patients bearing a variety of malignancies have been published. ${ }^{24-26}$ In particular, blocking of antibodies against PD-1 and PD-L1 has shown clinical activity in NSCLC.

Due to the rarity of pulmonary LELC, little is known about the biology of this neoplasm. In this work, we investigated the expression status of PD-L1 in patients with pulmonary LELC. Our results showed that a large proportion of patients with pulmonary LELC had positive expression of PD-L1, supporting the potential use of anti-PD-1/PD-L1targeted therapies in this distinct type of NSCLC.

\section{Materials and methods}

\section{Patients}

A total of 79 consecutive patients with pulmonary LELC from January 2001 to December 2013 were enrolled in this study. As previously reported, ${ }^{6}$ patients with negative EBV-encoded RNA staining were excluded from this study. Nasopharyngoscopy or positron emission tomography-computed tomography was conducted to rule out lung metastasis from nasopharyngeal carcinoma. Sun Yat-sen University Cancer Center research ethics board approved use of the data in this study, and informed consent for use and publication of patients' medical information was obtained from all patients at their first visit.

We restaged all patients based on the American Joint Committee on Cancer staging system (2007 TNM Classification of Malignant Tumors), ${ }^{27}$ and both clinical and pathological characteristics were reviewed.

\section{Immunohistochemical analysis of PD-LI expression}

Anti-PD-L1 rabbit polyclonal antibody was purchased from Abcam (Cambridge, UK). Immunohistochemical staining was performed as previously described ${ }^{28}$ and a two-stage immunohistochemical kit (ChemMate ${ }^{\mathrm{TM}}$ Envision Detection Kit, Peroxidase/DAB, Dako, Glostrup, Denmark) were used. PD-L1 immunostaining was classified into two groups according to intensity and extent: negative, when no staining or positive staining was detected in $<5 \%$ of the cells; and positive, when membranous staining was present in $\geq 5 \%$ of the cells. The $5 \%$ threshold was based on a previous Phase I trial of anti-PD-1 agents ${ }^{24}$ and studies involving other malignancies. ${ }^{20}$ Two independent pathologists (ZXK and CJW) assessed the expression intensity and extent of PD-L1.

\section{Statistical analysis}

The correlation of PD-L1 expression with various clinicopathologic parameters was assessed using the chi-squared test or Fisher's exact test after transforming into categorical values. Progression-free survival (PFS) and overall survival (OS) were calculated by the Kaplan-Meier method, while the log-rank test was used for comparison. The prognostic factors of OS and PFS were analyzed by univariate analysis. Multivariate analysis was performed using the Cox proportional hazard model to compare the factors proven significant in the univariate analysis. Hazard ratios and $95 \%$ confidence intervals were calculated for all variables in the regression model. A two-sided $P$-value $<0.05$ was considered to be statistically significant. Statistical Package for the Social Sciences version 19 statistical software (SPSS Inc, Chicago, IL, USA) was utilized. 


\section{Results}

\section{Clinical characteristic of patients with pulmonary LELC}

The patients' clinical characteristics are shown in Table 1. Thirty-nine patients (49.4\%) were male and 40 (50.6\%) were female. The median age at diagnosis was 52 (range 11-74) years. Only $22(27.8 \%)$ patients were smokers. The stages at initial diagnosis were: 25 (31.6\%) in stage I, 19 (24.1\%) in stage II, 33 (41.8\%) in stage III, and two (2.5\%) in stage IV. Most patients (67.1\%) had a tumor size larger than $3 \mathrm{~cm}$. In this cohort, 38 patients (48.1\%) received radical surgery alone, 35 patients $(44.3 \%)$ received a multimodality treatment strategy (radical surgery combined with radiotherapy or chemotherapy), and six patients $(7.6 \%)$ received palliative chemotherapy.

\section{Expression of PD-LI and relationship between PD-LI expression and clinical factors}

Pulmonary LELC was characterized by poorly differentiated or undifferentiated carcinoma cells located in syncytial sheets and nests. A great number of reactive lymphocytes and other inflammatory cells infiltrated the stromal tissue septa (Figure 1).

Of 79 patients, $50(63.3 \%)$ had PD-L1-positive tumor cells, usually of moderate-to-strong intensity (Figure 1B-F). The remaining 29 patients $(36.7 \%)$ showed a complete

Table I Patient characteristics

\begin{tabular}{|c|c|c|c|}
\hline Variables & $\begin{array}{l}\text { PD-LI-positive } \\
(n=50)\end{array}$ & $\begin{array}{l}\text { PD-LI-negative } \\
(n=29)\end{array}$ & $P$-value \\
\hline \multicolumn{4}{|l|}{ Gender } \\
\hline Male & 23 & 16 & 0.432 \\
\hline Female & 27 & 13 & \\
\hline \multicolumn{4}{|c|}{ Age, years } \\
\hline$\geq 60$ & 10 & 5 & 0.763 \\
\hline$<60$ & 40 & 24 & \\
\hline \multicolumn{4}{|c|}{ Smoking history } \\
\hline Yes & 13 & 9 & 0.630 \\
\hline No & 37 & 20 & \\
\hline \multicolumn{4}{|l|}{ Stage } \\
\hline I-II & 28 & 16 & 0.943 \\
\hline III-IV & 22 & 13 & \\
\hline \multicolumn{4}{|c|}{ Tumor size } \\
\hline$>3 \mathrm{~cm}$ & 36 & 17 & 0.223 \\
\hline$\leq 3 \mathrm{~cm}$ & 14 & 12 & \\
\hline \multicolumn{4}{|c|}{ Disease progression or relapse status } \\
\hline Yes & 7 & 13 & 0.002 \\
\hline No & 43 & 16 & \\
\hline \multicolumn{4}{|c|}{ Alive status } \\
\hline Dead & 3 & 8 & 0.020 \\
\hline Alive & 47 & 21 & \\
\hline
\end{tabular}

Abbreviation: PD-LI, programmed cell death-ligand I. absence of membrane staining or $<5 \%$ immunoreactivity (Figure 1A). As shown in Table 1, there was no significant difference in the positive expression rate of PD-L1 between different subgroups regarding gender, age, smoking history, stage, or tumor size $(P \geq 0.05)$. However, more patients in the PD-L1-negative group had disease relapse or progression than those in the PD-L1-positive group (44.8\% versus $14.0 \%$, respectively; $P=0.002$ ). Furthermore, more patients in the PD-L1 negative group died than in the PD-L1-positive group (27.6\% versus $6.0 \%$, respectively; $P=0.020$ ).

\section{PD-LI expression was associated with clinical outcomes}

The median follow-up duration for this cohort was 35.02 (6.57-159.05) months. The 3-year and 5-year OS rate was $88.0 \%$ and $79.0 \%$, respectively. During the follow-up period, 20 patients had disease relapse or progression at a median of 15.03 (1.45-70.74) months, and the 3-year and 5-year PFS rate was $76.0 \%$ and $68.0 \%$, respectively. Kaplan-Meier analysis revealed that patients with positive PD-L1 expression had longer PFS and OS than those with negative PD-L1 expression ( $P=0.019$ and $P=0.042$, respectively; Figure $2 \mathrm{~A}$ and $\mathrm{C}$ ), and patients with advanced stage (III-IV) disease had significantly inferior PFS and OS (both $P=0.000$; Figure $2 \mathrm{~B}$ and D). As shown in Table 2, in a multivariate Cox regression model including age, tumor size, stage, and PD-L1 expression status, the latter three factors were found to be independent predictors of PFS ( $P=0.023, P=0.000$, and $P=0.009$, respectively), but only stage was found to be an independent prognostic factor for OS $(P=0.007)$ and PD-L1 expression status showed a trend to be independently correlated with OS $(P=0.080)$.

\section{Discussion}

The aim of this study was to analyze the expression of PD-L1 in patients with pulmonary LELC and to evaluate its clinical relevance. We observed that about $63 \%$ of patients with pulmonary LELC had positive expression of PD-L1 in tumor cells. Importantly, tumors expressing PD-L1 in our series showed a significant trend toward better PFS.

PD-L1 is frequently expressed in many types of human cancer, and its interaction with PD-1 has been shown to induce apoptosis or exhaustion in activated T-cells. PD-L1/ PD-1 blockade has also been shown to enhance the antitumor activity of T-cells. ${ }^{18,29}$ Because of its role in tumor development, the prognostic significance of PD-L1 has been investigated in several studies and found to be associated with a worse outcome in several types of neoplasm, including NSCLC..$^{20,22,30-32}$ In contrast with the previous studies, our findings did not support positive PD-L1 expression being a 

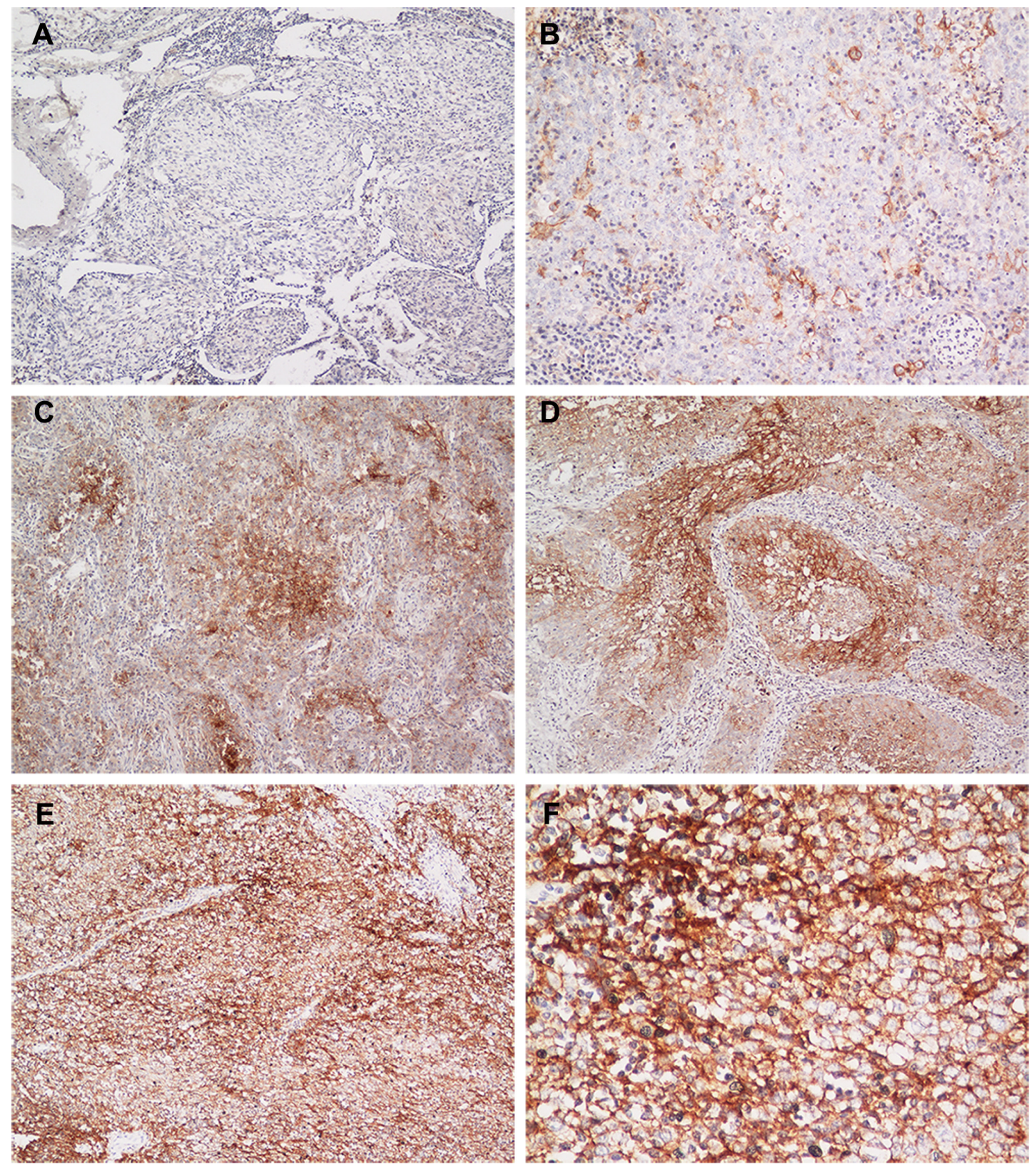

Figure I Immunohistochemical staining of PD-LI in patients with primary pulmonary lymphoepithelioma-like carcinoma.

Notes: (A) Negative PD-LI expression ( $\times 100)$, (B) PD-LI was expressed in 5\%-10\% of tumor cells $(\times 200)$, (C) PD-LI was expressed in 50\% of tumor cells ( $\times$ I00), (D) PD-LI was expressed in $80 \%-100 \%$ of tumor cells $(\times 100)$, (E) PD-LI was expressed in 100\% tumor cells $(\times 100)$, and (F) PD-LI was strongly expressed mainly in the membrane $(\times 400)$. Abbreviation: PD-LI, programmed cell death-ligand I.

poor prognostic factor for pulmonary LELC. In our study, multivariate analysis revealed that positive PD-L1 expression was significantly associated with better PFS $(P=0.009)$. Moreover, positive PD-L1 expression showed a trend toward being independently correlated with longer OS $(P=0.080)$. Association of PD-L1 expression with favorable outcome has also been observed in lung cancer, ${ }^{33,34}$ colon cancer, ${ }^{35}$ Merkel cell carcinoma, ${ }^{36}$ and melanoma. ${ }^{37}$

Although the reasons for these discrepancies concerning the prognostic value of PD-L1 in different studies remain unclear, the following observations might be possible explanations. Firstly, a different definition for high PD-L1 expression might be related to different results. An earlier study ${ }^{23}$ chose only the median value of the percentage of tumor cells positive for PD-L1, while other studies used a semiquantitative $\mathrm{H}$-score, and the cut-off value was the median of the H-score. ${ }^{31,34}$ Our study chose the threshold of $5 \%$, which has been used in clinical studies for analysis of PD-L1 expression in other malignancies, ${ }^{33,38}$ and this cutpoint is reported to be associated with clinical response to 
A

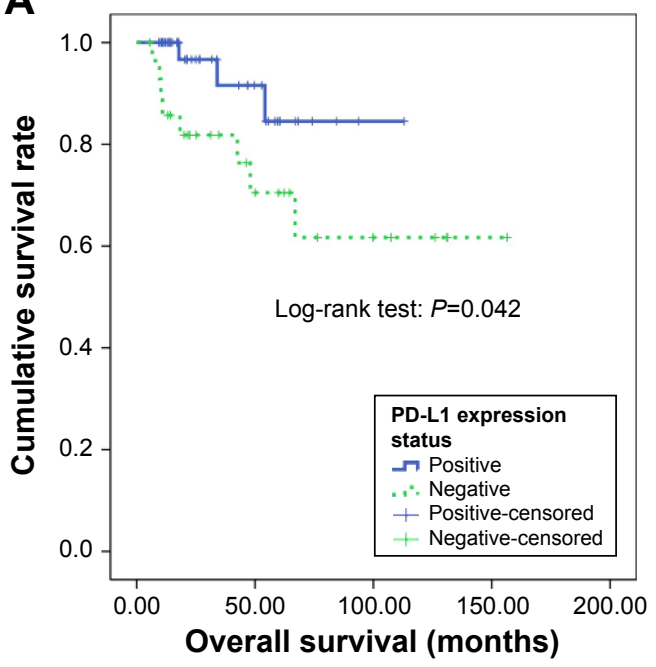

C

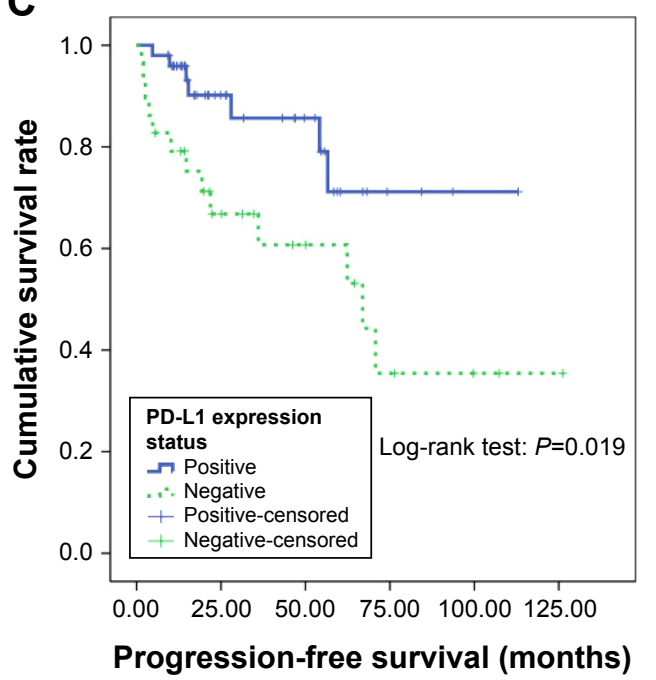

B

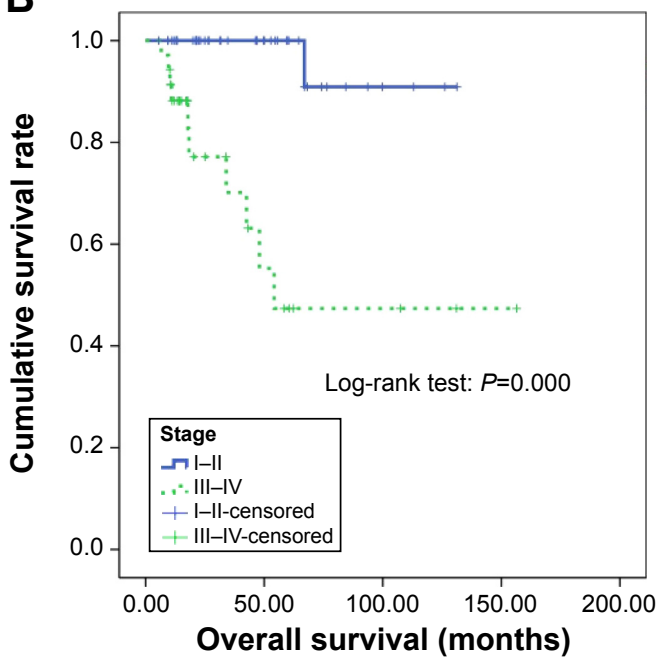

D

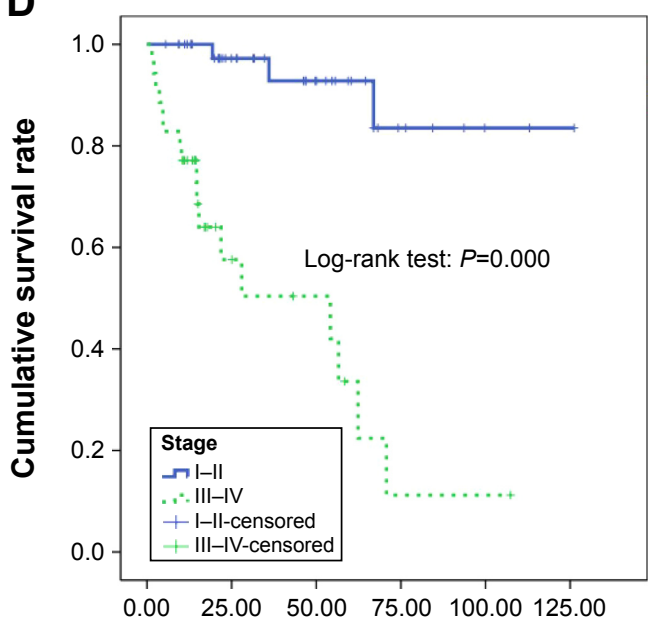

Progression-free survival (months)

Figure 2 Kaplan-Meier survival curves.

Notes: (A) Positive PD-LI expression was associated with better overall survival ( $P=0.042)$. (B) Advanced stage (III-IV) disease was associated with inferior overall survival $(P=0.000)$. (C) Positive PD-LI expression was associated with better progression-free survival $(P=0.019)$. (D) Advanced stage (III-IV) disease was associated with inferior progression-free survival $(P=0.000)$.

Abbreviation: PD-LI, programmed cell death-ligand I.

anti-PD-1 therapy. ${ }^{26}$ We also tested some other cut-off values to investigate the prognostic role of PD-L1, such as $10 \%$, $20 \%$, or $50 \%$, and found that $5 \%$ was the most appropriate one to be of prognostic value (data not shown). Secondly, the staining protocols or paraffin used for embedding may differ between these studies. Finally, different tumors have different biologic behaviors, and the systemic immunologic environment may affect the tumor growth to varying degrees.

Since Begin et al first reported pulmonary LELC in 1987, the association of EBV infection with pulmonary LELC

Table 2 Multivariate Cox regression survival analysis

\begin{tabular}{|c|c|c|c|c|c|c|}
\hline \multirow[t]{2}{*}{ Variables } & \multicolumn{3}{|l|}{ PFS } & \multicolumn{3}{|l|}{ OS } \\
\hline & HR & 95\% $\mathrm{Cl}$ for $\mathrm{HR}$ & $P$-value & HR & 95\% Cl for $\mathrm{HR}$ & $P$-value \\
\hline Age, years $(\geq 60$ versus $<60)$ & 0.409 & $0.107-1.566$ & 0.192 & 0.403 & $0.049-3.279$ & 0.395 \\
\hline Tumor size, $\mathrm{cm}(>3$ versus $\leq 3)$ & 3.847 & $1.200-12.328$ & 0.023 & 2.786 & $0.698-11.122$ & 0.147 \\
\hline Stage (III-IV versus I-II) & 15.378 & $4.230-55.915$ & 0.000 & 17.590 & $2.2|4-139.75|$ & 0.007 \\
\hline PD-LI status (negative versus positive) & 3.862 & $1.409-10.587$ & 0.009 & 3.436 & $0.863-13.684$ & 0.080 \\
\hline
\end{tabular}

Abbreviations: PFS, progression free survival; OS, overall survival; HR, hazard ratio; $\mathrm{Cl}$, confidence interval; PD-LI, programmed death ligand-I. 
has been observed. The presence of EBV was indicated by in situ hybridization for EBV-encoded RNAs in all of our 79 patients. The natural history of malignancies linked with viral infections, which are frequently associated with chronic inflammation, is often influenced by the immunologic state of the host. The immune regulatory PD-L1/PD-1 axis may play a significant role in the development and progression of virusassociated cancers. Intratumoral expression of PD-L1 and/ or PD-1 has been shown in polyomavirus-associated Merkel cell carcinoma, ${ }^{36}$ hepatitis $\mathrm{B}$ virus-related hepatocellular carcinoma, ${ }^{39}$ human papillomavirus-associated head and neck cancer, ${ }^{40}$ EBV-associated nasopharyngeal cancer, ${ }^{41}$ and adult T-cell leukemia/lymphoma linked to human T-cell leukemia virus- $1 .^{42}$ In virus-associated malignancies, PD-L1 expression likely reflects both a host reaction to the tumor and the chronic inflammatory environment triggered by the presence of the virus. High lymphocyte infiltration and consequent upregulation of PD-L1 in a subset of virus-positive tumors may reflect both enhanced antigenicity associated with viral infection and virus-independent factors, such as E-selectin expression on vascular endothelium, which promotes egress of lymphocytes. ${ }^{36,43}$ In defined cancer types, TILs have been shown to be associated with an improved prognosis. ${ }^{44,45}$ Pulmonary LELC is characterized by an intensive lymphocytic infiltrate, which may explain its better outcome. Thus, our observation of positive PD-L1 expression in pulmonary LELC with better PFS could demonstrate a pre-existing tumor inflammatory environment as a consequence of virus triggering TILs.

Consistent with previous studies, ${ }^{6,46}$ most of the patients with pulmonary LELC in our series had early-stage resectable disease and a better prognosis. Radical surgery is the main approach used to cure this disease. For metastatic disease, palliative chemotherapy has been used with unknown efficacy due to the rarity of LELC. ${ }^{5}$ Moreover, EGFR mutations and ALK rearrangement are rare in pulmonary LELCs. ${ }^{6,12}$ Thus, EGFR-targeted and ALK-targeted therapies are not encouraging treatment strategies for patients with advanced or metastatic pulmonary LELC. Recent clinical trials found that inhibition of the PD-L1/PD-1 interaction with antibodies specific for these proteins had promising antitumor efficacy in patients with various malignancies, including NSCLC. ${ }^{25,26}$ Although our study is retrospective in nature and has a relatively small sample size, our results provide a rationale for future clinical investigations of the PD-L1/PD-1 axis as a target therapy in patients with pulmonary LELC whose tumor specimens have a high PD-L1 expression level.

In conclusion, this is the first report to demonstrate the expression of PD-L1 in pulmonary LELC, and it found a significant correlation between better PFS and PD-L1 positivity in a cohort of patients from a single institution. Further studies are required to clarify the molecular mechanisms responsible for regulation of PD-L1 expression in virus-associated malignancies and to provide a rationale for exploring immunotherapies, such as anti-PD-1 and anti-PD-L1, in a type of tumor that currently lacks effective treatment options for advanced disease.

\section{Acknowledgments}

We thank the physicians at Sun Yat-sen University Cancer Center for allowing us to include their patients. We also appreciate the cooperation of the pathologists at Sun Yat-sen University Cancer Center for their support. This work received grant support from the National Natural Science Foundation of China (contract/grant 81400159) and Medical Research Foundation of Guangdong Province (grant B2014158).

\section{Disclosure}

The authors report no conflicts of interest in this work.

\section{References}

1. Begin LR, Eskandari J, Joncas J, Panasci L. Epstein-Barr virus related lymphoepithelioma-like carcinoma of lung. J Surg Oncol. 1987;36(4): 280-283.

2. Franklin WA. Diagnosis of lung cancer: pathology of invasive and preinvasive neoplasia. Chest. 2000;117(4 Suppl 1):80S-89S.

3. Han AJ, Xiong M, Zong YS. Association of Epstein-Barr virus with lymphoepithelioma-like carcinoma of the lung in southern China. Am J Clin Pathol. 2000;114(2):220-226.

4. Ngan RK, Yip TT, Cheng WW, et al. Clinical role of circulating Epstein-Barr virus DNA as a tumor marker in lymphoepithelioma-like carcinoma of the lung. Ann N Y Acad Sci. 2004;1022:263-270.

5. Ho JC, Wong MP, Lam WK. Lymphoepithelioma-like carcinoma of the lung. Respirology. 2006;11(5):539-545.

6. Liang Y, Wang L, Zhu Y, et al. Primary pulmonary lymphoepitheliomalike carcinoma: fifty-two patients with long-term follow-up. Cancer. 2012;118(19):4748-4758

7. Chang YL, Wu CT, Shih JY, Lee YC. Unique $p 53$ and epidermal growth factor receptor gene mutation status in 46 pulmonary lymphoepithelioma-like carcinomas. Cancer Sci. 2011;102(1):282-287.

8. Italiano A, Saint-Paul MC, Caroli-Bosc FX, et al. Epidermal growth factor receptor (EGFR) status in primary colorectal tumors correlates with EGFR expression in related metastatic sites: biological and clinical implications. Ann Oncol. 2005;16(9):1503-1507.

9. Shaw AT, Yeap BY, Mino-Kenudson M, et al. Clinical features and outcome of patients with non-small-cell lung cancer who harbor EML4ALK. J Clin Oncol. 2009;27(26):4247-4253.

10. Mok TS, Wu YL, Thongprasert S, et al. Gefitinib or carboplatinpaclitaxel in pulmonary adenocarcinoma. $N$ Engl J Med. 2009;361(10): 947-957.

11. Camidge DR, Bang YJ, Kwak EL, et al. Activity and safety of crizotinib in patients with ALK-positive non-small-cell lung cancer: updated results from a phase 1 study. Lancet Oncol. 2012;13(10):1011-1019.

12. Wong DW, Leung EL, So KK, et al; University of Hong Kong Lung Cancer Study Group. The EML4-ALK fusion gene is involved in various histologic types of lung cancers from nonsmokers with wild-type EGFR and KRAS. Cancer. 2009;115(8):1723-1733.

13. Khoury SJ, Sayegh MH. The roles of the new negative T cell costimulatory pathways in regulating autoimmunity. Immunity. 2004;20(5): $529-538$. 
14. Okazaki T, Honjo T. The PD-1-PD-L pathway in immunological tolerance. Trends Immunol. 2006;27(4):19-201.

15. Freeman GJ, Long AJ, Iwai Y, et al. Engagement of the PD-1 immunoinhibitory receptor by a novel $\mathrm{B} 7$ family member leads to negative regulation of lymphocyte activation. J Exp Med. 2000;192(7):1027-1034.

16. Latchman Y, Wood CR, Chernova T, et al. PD-L2 is a second ligand for PD-1 and inhibits T cell activation. Nat Immunol. 2001;2(3):261-268.

17. Keir ME, Liang SC, Guleria I, et al. Tissue expression of PD-L1 mediates peripheral T cell tolerance. $J$ Exp Med. 2006;203(4):883-895.

18. Keir ME, Butte MJ, Freeman GJ, Sharpe AH. PD-1 and its ligands in tolerance and immunity. Annu Rev Immunol. 2008;26:677-704.

19. Iwai Y, Ishida M, Tanaka Y, Okazaki T, Honjo T, Minato N. Involvement of PD-L1 on tumor cells in the escape from host immune system and tumor immunotherapy by PD-L1 blockade. Proc Natl Acad Sci U S A. 2002;99(19):12293-12297.

20. Thompson RH, Gillett MD, Cheville JC, et al. Costimulatory B7-H1 in renal cell carcinoma patients: Indicator of tumor aggressiveness and potential therapeutic target. Proc Natl Acad Sci U S A. 2004;101(49): 17174-17179.

21. Strome SE, Dong H, Tamura H, et al. B7-H1 blockade augments adoptive T-cell immunotherapy for squamous cell carcinoma. Cancer Res. 2003;63(19):6501-6505.

22. Ohigashi Y, Sho M, Yamada Y, et al. Clinical significance of programmed death-1 ligand-1 and programmed death-1 ligand-2 expression in human esophageal cancer. Clin Cancer Res. 2005;11(8):2947-2953.

23. Konishi J, Yamazaki K, Azuma M, Kinoshita I, Dosaka-Akita H, Nishimura M. B7-H1 expression on non-small cell lung cancer cells and its relationship with tumor-infiltrating lymphocytes and their PD-1 expression. Clin Cancer Res. 2004;10(15):5094-5100.

24. Brahmer JR, Drake CG, Wollner I, et al. Phase I study of single-agent anti-programmed death-1 (MDX-1106) in refractory solid tumors: safety, clinical activity, pharmacodynamics, and immunologic correlates. J Clin Oncol. 2010;28(19):3167-3175.

25. Brahmer JR, Tykodi SS, Chow LQ, et al. Safety and activity of antiPD-L1 antibody in patients with advanced cancer. N Engl J Med. 2012; 366(26):2455-2465.

26. Topalian SL, Hodi FS, Brahmer JR, et al. Safety, activity, and immune correlates of anti-PD-1 antibody in cancer. $N$ Engl J Med. 2012; 366(26):2443-2454.

27. Shepherd FA, Crowley J, Van Houtte P, et al; International Association for the Study of Lung Cancer International Staging Committee and Participating Institutions. The International Association for the Study of Lung Cancer lung cancer staging project: proposals regarding the clinical staging of small cell lung cancer in the forthcoming (seventh) edition of the tumor, node, metastasis classification for lung cancer. J Thorac Oncol. 2007;2(12):1067-1077.

28. Gao Q, Wang XY, Qiu SJ, et al. Overexpression of PD-L1 significantly associates with tumor aggressiveness and postoperative recurrence in human hepatocellular carcinoma. Clin Cancer Res. 2009;15(3):971-979.

29. Blank C, Gajewski TF, Mackensen A. Interaction of PD-L1 on tumor cells with PD-1 on tumor-specific T cells as a mechanism of immune evasion: implications for tumor immunotherapy. Cancer Immunol Immunother. 2005;54(4):307-314.

30. Nomi T, Sho M, Akahori T, et al. Clinical significance and therapeutic potential of the programmed death-1 ligand/programmed death-1 pathway in human pancreatic cancer. Clin Cancer Res. 2007;13(7):2151-2157.

OncoTargets and Therapy

\section{Publish your work in this journal}

OncoTargets and Therapy is an international, peer-reviewed, open access journal focusing on the pathological basis of all cancers, potential targets for therapy and treatment protocols employed to improve the management of cancer patients. The journal also focuses on the impact of management programs and new therapeutic agents and protocols on
31. Azuma K, Ota K, Kawahara A, et al. Association of PD-L1 overexpression with activating EGFR mutations in surgically resected nonsmallcell lung cancer. Ann Oncol. 2014;25(10):1935-1940.

32. Hino R, Kabashima K, Kato Y, et al. Tumor cell expression of programmed cell death-1 ligand 1 is a prognostic factor for malignant melanoma. Cancer. 2010;116(7):1757-1766.

33. Velcheti V, Schalper KA, Carvajal DE, et al. Programmed death ligand-1 expression in non-small cell lung cancer. Lab Invest. 2014; 94(1):107-116.

34. Chen YB, Mu CY, Huang JA. Clinical significance of programmed death-1 ligand-1 expression in patients with non-small cell lung cancer: a 5-year-follow-up study. Tumori. 2012;98(6):751-755.

35. Droeser RA, Hirt C, Viehl CT, et al. Clinical impact of programmed cell death ligand 1 expression in colorectal cancer. Eur J Cancer. 2013;49(9):2233-2242.

36. Lipson EJ, Vincent JG, Loyo M, et al. PD-L1 expression in the Merkel cell carcinoma microenvironment: association with inflammation, Merkel cell polyomavirus and overall survival. Cancer Immunol Res. 2013;1(1):54-63.

37. Taube JM, Anders RA, Young GD, et al. Colocalization of inflammatory response with B7-h1 expression in human melanocytic lesions supports an adaptive resistance mechanism of immune escape. Sci Transl Med. 2012;4(127):127ra137.

38. Yang CY, Lin MW, Chang YL, Wu CT, Yang PC. Programmed cell death-ligand 1 expression in surgically resected stage I pulmonary adenocarcinoma and its correlation with driver mutations and clinical outcomes. Eur J Cancer. 2014;50(7):1361-1369.

39. Zeng Z, Shi F, Zhou L, et al. Upregulation of circulating PD-L1/PD-1 is associated with poor post-cryoablation prognosis in patients with $\mathrm{HBV}$ related hepatocellular carcinoma. PLoS One. 2011;6(9):e23621.

40. Badoual C, Hans S, Merillon N, et al. PD-1-expressing tumor-infiltrating $\mathrm{T}$ cells are a favorable prognostic biomarker in HPV-associated head and neck cancer. Cancer Res. 2013;73(1):128-138.

41. Hsu MC, Hsiao JR, Chang KC, et al. Increase of programmed death1-expressing intratumoral CD8 $\mathrm{T}$ cells predicts a poor prognosis for nasopharyngeal carcinoma. Mod Pathol. 2010;23(10):1393-1403.

42. Kozako T, Yoshimitsu M, Fujiwara H, et al. PD-1/PD-L1 expression in human T-cell leukemia virus type 1 carriers and adult T-cell leukemia/ lymphoma patients. Leukemia. 2009;23(2):375-382.

43. Afanasiev OK, Nagase K, Simonson W, et al. Vascular E-selectin expression correlates with CD8 lymphocyte infiltration and improved outcome in Merkel cell carcinoma. J Invest Dermatol. 2013;133(8): 2065-2073.

44. Klintrup K, Makinen JM, Kauppila S, et al. Inflammation and prognosis in colorectal cancer. Eur J Cancer. 2005;41(17):2645-2654.

45. Sato E, Olson SH, Ahn J, et al. Intraepithelial CD8+ tumor-infiltrating lymphocytes and a high $\mathrm{CD} 8+$ /regulatory $\mathrm{T}$ cell ratio are associated with favorable prognosis in ovarian cancer. Proc Natl Acad Sci U S A. 2005;102(51):18538-18543.

46. Han AJ, Xiong M, Gu YY, Lin SX, Xiong M. Lymphoepithelioma-like carcinoma of the lung with a better prognosis. A clinicopathologic study of 32 cases. Am J Clin Pathol. 2001;115(6):841-850.

patient perspectives such as quality of life, adherence and satisfaction The manuscript management system is completely online and includes a very quick and fair peer-review system, which is all easy to use. Visit http://www.dovepress.com/testimonials.php to read real quotes from published authors.

\section{Dovepress}

